\title{
SOCIAL NETWORKING FOR LIFE-LONG-LEARNING WITH QUALITY MANAGEMENT ASPECTS IN TECHNICAL TEACHING
}

\author{
Sonja Gögele \\ Institute of Internet-Technologies and-Applications, FH Joanneum, University of Applied Sciences
}

(Austria)

\begin{abstract}
The following paper has to be seen in connection with some well-known authors' statements asserting that in today's "knowledge society" individual knowledge and especially collective knowledge become more and more important. If knowledge is assumed to be part of a set of expectations held by today's social system, this new societal formation is less characterized by an increase of knowledge as a consequence of accumulating dates and information than by a basic change of people's meta-preferences. This is due to the fact that all societies are based on the knowledge of cognitive expectations. For this reason, the world or the knowledge society, respectively also appears to be a risk society. According to the system-theoretical approach knowledge can be seen as an emergent cognitive structure of social systems or as expectations directed towards the environment and its norms. These expectations have to be changeable if required. Disappointments or failures are observed and interpreted, thus creating so called structural effects that can also be referred to as learning. Empirical economic studies attempting to explain the determinants of investment in social capital have generally been limited in their definition of what constitutes an individual's social capital. The focus has almost exclusively been on participation in formal organisations, ignoring informal networks to which individuals belong. We discuss social capital investment which has been extended to also include measures of investment in social networks such as networks of family, friends and neighbours, and the relationship between learning groups in organisations. Social capital seen as a contemporary concept of social sciences cannot be reduced to a kind of social network of relations but has to be regarded as a communication structure of relations based on social systems. Thus, knowledge and norms are only a partial aspect of emergent structures of social systems. The new aspect on lifelong learning is how to build a social group with a sustainable new WE-feeling.
\end{abstract}

Keywords: eLearning, social capital, social networking, life-long-learning, community of practice.

\section{Introduction}

As the spatial and temporal conditions of knowledge continually change, new requirements concerning the social systems evolve. Such requirements imply for example the necessity to remain flexible and adaptive which partly clashes with modern habits and conditions of the success of formal organisations. Therefore, organised social systems aim to stabilise communication through decisions and to standardize their members' expectations of the social systems. Due to this fact and to a minimum of not changeable structures organizations will take on a lasting identity while at the same time our environment demands an increasing flexibility going hand in hand with a heightened willingness to learn. Some case studies in Germany in 2003 (cf. Kauffeld/Grote, 2000 p.95) have shown that there is a relationship between flexible organisations and the competences of the employees (i.e. self-organisation and social competences).

\section{Materials and methods}

This paper deals with possible learning structures taking place in the context of the degree study course Internet Technology and Management and its special programme Software Design which is primarily based on eLearning elements (in this case a blended learning environment is used). The learning structures are analysed in connection with their social background which can be interpreted as an attempt to create a phenomenology of how learning takes place in groups in a digital environment. Additionally, the conditions of social learning in groups are examined. The assumption that group dynamics in a real 
learning environment are equivalent to those in a virtual (eLearning) environment is theoretically dealt with. This assumption will finally be called into question by looking at it from a phenomenological, systemic and pedagogical point of view (cf. Rombach, Luhmann, Benner, Gruber, Böhnisch). Great importance is placed on the above mentioned learning groups because they encourage students to also communicate informally and even personally with each other. Thus, emotions besides cognitions are also recognised as an integral part of social structuring. In this case feelings supposedly serve as an immune system of disappointed expectations and as a mechanism that substitutes organisational formalizations in order to reduce the complexity of learning processes within an organization.

The demands on real and virtual learning groups are numerous and to a certain extent also contradictory. At times, one could even get the impression that the idea of social learning groups is propagated as an almost universal solution for unresolved problems of traditional organizations in our knowledge society.

Within all organizations, there exists a formal structure that is described by boxes, arrows, documented policies and procedures. This formal structure may be contrasted with a less formal environment that is more based on self-organized group interactions and individual relationships. Behind every organization chart lie informal clusters and networks of employees who work together - sharing knowledge, solving common problems and exchanging insights, stories and frustrations. When appropriately supported by the formal organization these "communities of practice," as they are often called, play a critical role: they are the major building blocks in creating, sharing and applying organizational knowledge.

To create, expand, and exchange knowledge, and to develop individual capabilities are according to Wenger the characteristic tasks for "Communities of Practice". Thus, most of these groups are also "Keeping Communities", in other words, they represent a platform of geographically distant but still present knowledge to solve problems. Through legitimate peripheral participation they support and assist their members in the socialisation process. This means that the learning group in the process of gradually acquiring knowledge also takes on the role of a so called "Innovating Community" that supports and further develops ideas. In order to establish a useful and realistic frame of reference for eLearning it is important that the community is seen as a characteristic entity which differentiates itself from traditional social fabrics. The aim of this theoretical understanding is to develop and form in the context of education and knowledge acquisition a virtual room of possibilities which is also close to reality.

Social capital refers to the social resources individuals within a community draw upon and provide value to themselves and their organizations. These social resources include common identity, familiarity, trust, and a degree of shared language and context among individuals. These resources manifest themselves in a variety of ways, including reducing the time it takes to locate an expert within an organization, minimizing the costs associated with validating expertise and reducing the time and effort associated with developing and monitoring an agreement between individuals in an organization. All of these activities enable an organization to better manage its knowledge resources. Much like financial or human capital, social capital can be fostered and tapped as needed to enable individuals to perform their jobs more efficiently and effectively. In this paper, we hypothesize that social networks for life-long-learning are valuable to organizations because they contribute to the development of social capital, which in turn is a necessary condition for knowledge creation, sharing and use.

The social learning group which is pursued within the scope of the degree study course Internet Technology and Management and its part-time programme Software Design does not only relate to the lecturers working on particular topics. The lecturers are also supposed to initiate communities for their students in order to generate an evolutionary process concerning the groups as well as the topics.

The formation of a social network as an organism that acquires knowledge is thus be seen against a very diversified and multi-facetted background. This is especially true if the (continually developing) stock of knowledge is embedded in the context of work, social and systemic structures, social assets and the fact that the identity of the learning individual changes.

While having a network of individuals is a critical part in developing social capital, equally as important are the interpersonal dynamics between individuals within the network. This relational dimension addresses issues around trust, shared norms and values, obligations, expectations and identification that are critical in developing a social network among members of a group. Francis Fukuyama states, "Trust is the expectation that arrives within a community of regular, honest and cooperative behaviour, based on commonly shared norms on the part of other members of that community... Social capital is the capability that arises from the prevalence of trust in a society or in certain parts of it. It can be embodied in the smallest and most basic social group, the family, as well as the largest of all groups, the nation and in all the other groups in between. Social capital differs from other forms of human capital insofar as it is usually created and transmitted through cultural mechanisms like religion, tradition or historical habit." 


\section{Results}

The phenomenological analysis of the phenomena observed during the eLearning sessions of the virtual degree programme serves as a basis for the understanding of a virtual and social frame of reference. Thus, a Community of Practice is created (cf. Rombach). On the other hand, it is also important to try and reduce the complexity of systemic procedures if a useful reduction of social processes should be developed (cf. Luhmann).

We assume that the presence of the WE-feeling as a kind of social capital in a learning group has a greater positive impact on knowledge creation when the members believe in the WE-feeling. Using the three dimensions of real and virtual learning groups - structural, relational and cognitive - we would like to illustrate how the circle around the WE-feeling - in all three dimensions - in the social networks plays an interdisciplinary and multidimensional role in the development of social network for life-long-learning.

\subsection{Structural dimension}

Individuals develop a network with persons who have similar interests - this works the same way in traditional and in virtual groups. First, they serve as an intra-network clearinghouse by identifying those with relevant knowledge and helping individuals within the learning group make connections with one another. This is particularly valuable as the organization goes "virtual" and individuals find it increasingly difficult to know "who knows what." Second, they act as a reference mechanism, quickly enabling individuals to evaluate the knowledge of other members without having to contact each individual within the network. Third, they connect individuals from outside the network - other teachers and other students - to those who are already identified as community members. We interpret this as the first step to create the WE-feeling. Therefore, it is necessary to connect our two communities (virtual student's community and the virtual trainer's community) to an informal social group and then build a virtual team together. If this team exists longer than the necessary learning circle (that means: after the examinations) the WE-feeling in a virtual social network has begun to work.

\subsection{Relational dimension}

By being able to bring people together to create and share relevant knowledge, the community creates the condition where individuals can be an individual in a group. So this is a process taking place in a certain period of time and is, like Fukuyama named it, an "informal currency" in the learning group with norms and values that are generally accepted. The individuals can develop empathy for the situations of others and can establish rapport with individuals in the community.

\subsection{Cognitive dimension}

Communities of practice help shape the actual terminology used by group members in everyday work conversations. In addition, they generate and share the knowledge objects or "artifacts" that are used by community members. The virtual learning group generates stories that communicate the norms and values of the community and of the organization as a whole. These stories also generate the new WE-feeling in the members of the social group. After some time the group has its own memory that perpetuates itself long after the original community members have departed and we hope so long after the degree study will be ended.

The objective of our virtual learning communities is to form and develop a group identity in terms of the new evolutional "WE". Time, space and content are significant parameters that differentiate these knowledge communities from traditional social fabrics; none the less it seems that the development of such communities corresponds to a large degree to socio-genetic formations if the frame of reference also creates a field of sense (cf. Rombach, 287). It is a field of sense that has been formed creatively and that has also matured to become an ontological authenticity. 


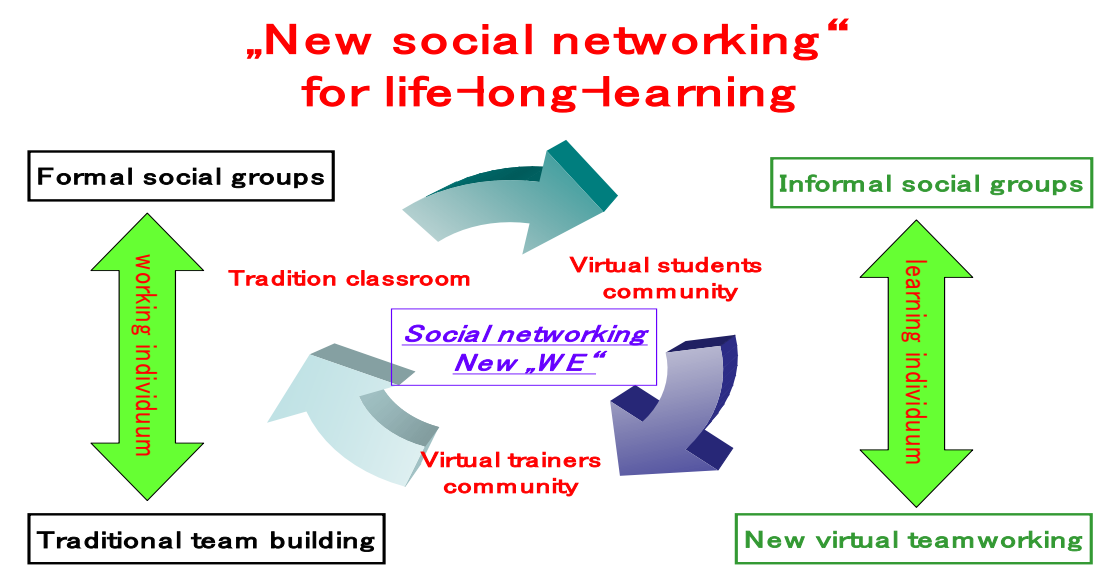

After closing the circle between traditional team building and new virtual team working it will be possible to do social networking with a sustainable WE-feeling for the lifelong learning process. By continually referring to the subsystems the creation of a common knowledge oriented and content oriented structure of conscience which is seen as an individual formation of identity and as part of a social fabric should preserve, reinforce and further develop the solidarity to the community.

eLearning (eLearning in our context means blended learning with 60:40 (traditional: virtual)) within a social network is regarded as a cyclical interplay of social substructures of knowledge and their own characteristic identities. A prerequisite for this interplay is that the traditional learning environment becomes a Community of Practice in which both the "Community of Virtual Trainers" and the "Community of Virtual Students" work together. In this case the Communities of Practice are less a part of the formal social systems the learning individual is part of, but rather an integral part of informal social learning structures. The tasks, which in this case are the learning objectives of the community, forms the consciousness of the Communities of Practice within the learning structure. The collective individual that is also a changeable parameter within this lifelong process of learning has the opportunity to finally identify with this consciousness. This must be seen as a continuous improvement process in the eLearning quality management system.

The human being in its role as a social individual adapts itself during this lifelong learning process to the changing environment (in our case the learning environment or the medium of learning). The individual as part of the learning community whose sole purpose is no longer just to acquire knowledge in order to satisfy social expectations requires in addition to some informal also some personal, emotional and affective communication. These human and interpersonal factors are major conditions for forming social learning groups. The learning individual needs to find a representation of its social structures in the virtual world in order not to be degraded to a functioning monad in an "education of usability" (cf. Gruber).

The part-time programme Software Design of the degree course Internet Technology and Management tries to support and develop a Community of Practice as a social system which is primarily based on communication and which is in some parts self-referential and auto-poietic (cf. Maturana and Varela). In this sense, our communities are regarded as group structures that do not end up in formal organisational structures but that will rather outlive them as far as content and continuity are concerned. By doing so a lasting relation to the group, the educational institution FH JOANNEUM and the subject matter IT that goes beyond the duration of their studies should be achieved. This kind of relationship of individuals to and within the Communities seems to be a factor that accompanies the lifelong process of learning, especially if we emphasize the importance of affective and emotional tensions. We interpret this gap between knowledge acquisition / processing and social needs according to a humanistic world view and proceed on the assumption that these, from an evolutionary perspective, early mechanisms contribute a lot to the latency of these communities.

The communicative approach and the development of key qualifications that are necessary for these communities but that still need to be cultivated are major concerns of the degree study course Internet Technology and Management and its part-time programme Software Design. In this context it has to be pointed out that due to our innovative teaching methods (eLearning) the average age of the students of Software Design is decisively higher than that of the fulltime programme. 


\section{Conclusion}

Communities of practice play a critical role in the day-to-day activities of organizations. One of their key functions is to build social capital among organization members, which in turn enables community members to more effectively manage their organizational knowledge. This paper has illustrated the most important connections between communities of practice, social capital and social networking. We are certain that these thoughts will help learning organizations and learning groups to manage their knowledge and lead to improved socialized learning processes for life-long-learning.

The aim of this paper is to present and explain our experiences in a virtual learning and teaching environment. The observations made during the two years of running the part-time programme Software Design enable a detailed analysis of our eLearning environment. This process of analysis was accompanied by evaluations carried out among students and lecturers and the developers of our eLearning and communication platform (Moodle or eNcephalon). The platform is supposed to accompany the learning process and to serve as a permanent room for the Communities.

The research field of social networking as well as the significance of the impact of eLearning on social networks forms a counterpoint to the technical and technological research work of the degree study course Internet Technology and Management and its special programme Software Design. It is assumed that social capital in form of confidence or solidarity within a group stabilises its relations and forms a social room which protects its members against negative influences of any kind. On the one hand side, this would lead to a better learning climate and a heightened innovative and experimental behaviour of the students. On the other hand-side, established traditions and approved ideas would be preserved and finally passed down to the next generation of students and lecturers. A better understanding of these interactions seems to be best achieved by a continuous process of observation carried out by the lecturers as well as the students.

\section{References}

Ackoff (1994): The Democratic Corporation, New York/Oxford: Oxford University Press.

Benner (2001): Allgemeine Pädagogik, Juventa, Weinheim, München.

Böhnisch (2001): Sozialpädagogik der Lebensalter, Juventa, Weinheim, München.

Fukoyama (1995): Trust: The social virtues and the creation of prosperity, Free Press Paperbacks.

Gomez; Zimmermann (1992): Unternehmensorganisation. Profile - Dynamik -Methodik, St. Galler Management-Konzept, 2. Aufl., Frankfurt/New York: Campus (1. Aufl. 1992).

Gruber (1997): Bildung zur Brauchbarkeit, Profil, Wien.

Hohm (2000): Soziale Systeme, Kommunikation, Mensch. Eine Einführung in die soziologische Systemtheorie. Weinheim und München.

Kauffeld (2000): Haben flexiblere Unternehmen kompetentere Mitarbieter? In: Frieling/Kauffeld/Grote/Bernard: Flexibilität und Kompetenz, Waxmann, 2000.

Loss (1999): Gestaltkonzepte in der Analyse von Organisationen - in - Handbuch der Gestalttherapie, Hogrefe, Göttingen, Bern, Toronto.

Pechtl (2001): Zwischen Organismus und Organisation, Landesverlag, St. Pölten.

Rombach (1988): Strukturonthologie - eine Phänomenologie der Freiheit, Alber, Freiburg, München.

Rombach (1993): Strukturanthropologie, Alber, Freiburg, München.

Rombach (1994): Phänomenologie des sozialen Lebens, Alber, Freiburg, München.

Tergan; Schenkel (2004): Qualität von E-Learning: eine Einführung. In: Tergan, S.-O.; Schenkel, P. (Hrsg.). Was macht E-Learning erfolgreich? Grundlagen und Instrumente der Qualitätsbeurteilung. Springer-Verlag, Berlin.

Watzlawick, Paul (2005): Kurzzeittherapie und Wirklichkeit, Piper, München 